\title{
Development of a Low-Cost and Vibration-Free Constant-Temperature Chamber for Precision Measurement
}

\author{
Jian Feng ${ }^{1}$, Rui-Jun Li ${ }^{1, *}$, Kuang-Chao Fan ${ }^{1,2}$, Hao Zhou ${ }^{1}$ and Hui Zhang ${ }^{1}$ \\ ${ }^{1}$ School of Instrument Science and Opto-electronic Engineering, \\ Hefei University of Technology, Hefei 230009, China \\ ${ }^{2}$ Department of Mechanical Engineering, National Taiwan University, Taipei, Taiwan
}

(Received August 18, 2014; accepted March 12, 2015)

Key words: constant-temperature chamber, thermoelectric cooler, natural convection principle, vacuum insulation plate

A low-cost high-precision constant-temperature mini chamber based on the natural convection principle is presented in this paper. The chamber is assembled using hollow acrylic walls whose sizes are tailored according to the required space. A thin layer of vacuum insulation plate (VIP) with an ultralow thermal conductivity coefficient is adhered around the inner walls so as to prevent heat exchange with room air. A highprecision temperature sensor measuring the temperature near the instrument's measuring point provides a feedback signal to a proportional integral derivative (PID) controller. Thermoelectric coolers uniformly arranged on the ceiling of the chamber are used to cool the air inside the chamber directly without any air supply system, yielding a vibrationfree cooling system. A programmable power supply is used as the driver for the coolers to generate different cooling capacities. In practice, the down-flowing cool air and the up-flowing hot air form a natural convection, and the air temperature in the chamber gradually becomes stable and finally reaches the temperature set by the PID controller. Experimental results show that the system's steady-state error is $0.0043{ }^{\circ} \mathrm{C}$ on average, and the variation range is less than $\pm 0.02{ }^{\circ} \mathrm{C}$ when the set temperature is $20^{\circ} \mathrm{C}$, which is much better than the requirement of a Class I standard room. This innovative low-cost, vibration-free, and low-energy-consumption temperature-controlled chamber can be used in micro/nanomeasurement or manufacturing applications and its volume can be customdesigned for any equipment.

\section{Introduction}

In the field of micro/nanotechnologies, such as measurement, fabrication, and operation, the demands on high accuracy and precision require a high-precision temperature-controlled environment to minimize the effects of thermal expansion. ${ }^{(1-6)}$ It

${ }^{*}$ Corresponding author: e-mail: rj-li@hfut.edu.cn 
was proved that the error will increase to $10 \mathrm{~mm}$ owing to the thermal deformation of the system's mechanical structure if the environment temperature varied $1{ }^{\circ} \mathrm{C} .{ }^{(7)}$ Usually, most precision laboratories construct expensive and spacious constant-temperature rooms to enclose all equipment and operators. In this case, thermal isolation for the entire room and a high-power air conditioner are needed. It not only requires high cost and high energy consumption, but the indoor activities will also affect the temperature stability. These disadvantages can be avoided by controlling the temperature surrounding the equipment only, rather than the entire room's temperature. This is the concept of "Mini Environment".

A mini environment is a localized environment created by an enclosure to isolate from the surrounding environment. International Organization for Standardization (ISO) and the Institute of Environmental Science and Technology (IEST) have published the construction and operation methods or protocols for mini environments and clean rooms. ${ }^{(8-10)}$ In recent years, this concept has not only been used to achieve a constant-temperature/ humidity environment extensively, but also to maintain a level of stringent cleanliness by controlling particle concentrations within a tightened volume of clean space. ${ }^{(11,12)}$ Compared with constructing a room, the advantages of a mini environment include (1) higher precision, (2) lower cost, (3) good controllability, (4) lower energy consumption, and (5) immunity to personal activity.

Some mini environment chambers with various devices, materials, and physical configurations have been developed. The National Institute of Standard and Technology (NIST) developed a spherical temperature chamber with a multiplayer so as to minimize the measurement uncertainty of an invented molecular measuring machine. ${ }^{(1)} \mathrm{A}$ temperature stability of $20 \pm 0.001{ }^{\circ} \mathrm{C}$ has been demonstrated when the room is kept at $17 \pm 0.01{ }^{\circ} \mathrm{C}$. The Billionth Uncertainty Precision Engineering (BUPE) constructed a high-precision constant-temperature chamber for an ultraprecision coordinate-measuring machine (UPCMM). ${ }^{(7)}$ The cuboid chamber includes four layers, namely, an adiabatic layer, an acoustic insulation layer, a vacuum layer, and a measurement layer. The temperature stability in the measurement layer can reach $20 \pm 0.001{ }^{\circ} \mathrm{C}$. The Pathumwan Institute of Thailand developed a two-layer spherical chamber with the stability of 0.01 ${ }^{\circ} \mathrm{C}$ for scanning tunneling microscopy (STM). ${ }^{(13)}$ Many other research institutes have studied the temperature-controlled environment for nanotechnology application. ${ }^{(2-6)}$ The above-mentioned chambers have high precision and high stability. However, they are very complicated, expensive, and difficult to manufacture.

A separate constant-temperature environment chamber has been developed by our group. ${ }^{(14,15)}$ The chamber is composed of three separate chambers, namely, a constanttemperature chamber, a static-pressure chamber, and a refrigeration chamber. Although it could stabilize the temperature within the chamber at a low cost, the requirement of two blowers to force air flow through the duct, however, will induce noise and vibration to the constant-temperature chamber. Meanwhile, the separate construction makes the setup bulky and expensive.

In this research, we developed a single low-cost constant-temperature mini chamber with the stability of $20 \pm 0.02{ }^{\circ} \mathrm{C}$, which is composed of a refrigeration layer on top to produce cooling air, a perforated plate to generate laminar air flow, and a thermal 
insulation chamber to maintain constant temperature. The temperature stability is based on the natural convection between the down-flowing cold air and the up-flowing hot air under steady-state condition. Measurement errors can be minimized by reducing contamination in the air and removing the effect of operators. ${ }^{(16)}$ The constanttemperature chamber has the advantages of low cost, low energy consumption, no vibration, high precision, and high stability.

\section{Materials and Methods}

\subsection{Structure of the chamber}

The constant-temperature chamber shown in Fig. 1 is specially designed for a micro/ nano coordinate measuring machine $(\mathrm{CMM})$ developed by our group. ${ }^{(2,17)}$ The size of the chamber is $0.68 \times 0.68 \times 0.8 \mathrm{~m}^{3}$. To make the temperature field more uniform, the chamber was divided into two parts by a steady-flow perforated plate mounted on vertical supports with a bracket: one is the constant-temperature chamber and the other is the refrigeration chamber. The diameter of the holes on the steady-flow plate is $5 \mathrm{~mm}$ and the interval of the holes is $20 \mathrm{~mm}$. Nine thermoelectric coolers used to cool the air inside the refrigeration chamber are arranged uniformly on the ceiling of the chamber. The down-flowing cool air and the up-flowing hot air form a natural convection, and the air temperature in the chamber gradually stabilizes. Compared with the separate constant-temperature chamber, there is no vibration because no air supply system is adopted.

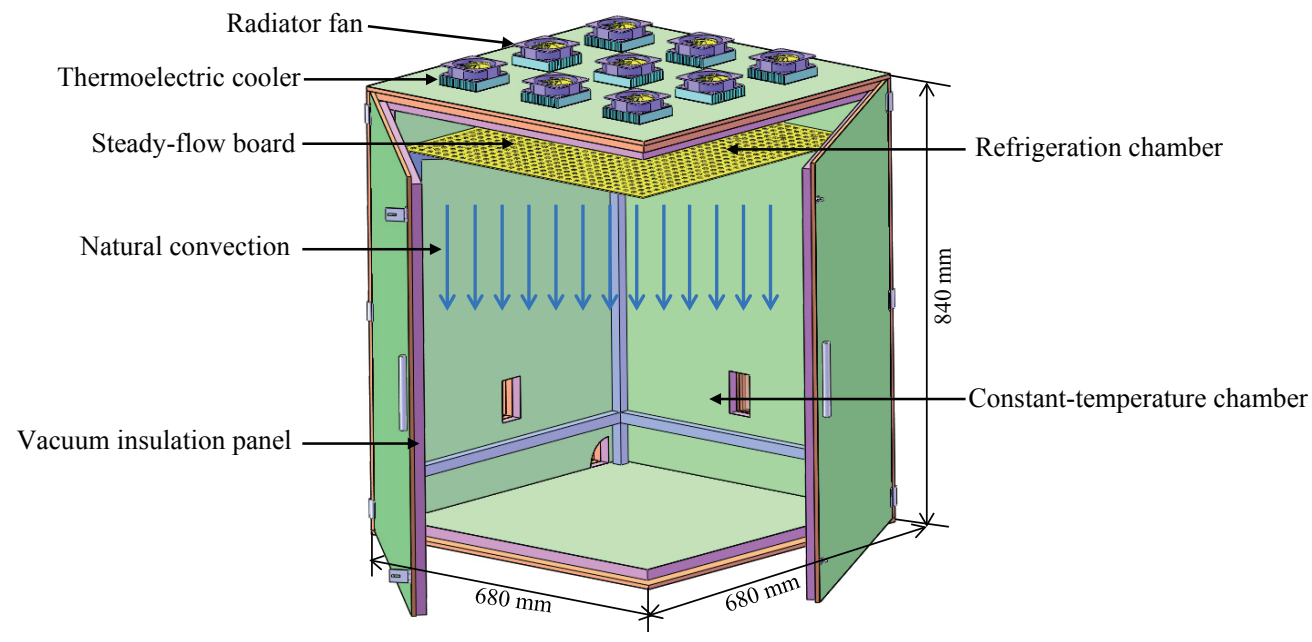

Fig. 1. (Color online) Layout of the constant-temperature chamber. 
The walls of the chamber are made of hollow polymethyl methacrylate (PMMA) upon which a lightweight thin vacuum insulation plate (VIP) with an ultralow thermal conductivity coefficient is adhered, as illustrated in Fig. 2. The VIP is recognized by the International Energy Agency for reducing the energy consumption of buildings. ${ }^{(18)}$ It is made of nanoporous silica powder as the core material and a multilayer membrane with metalized polymer films as the gas barrier envelope, as shown in Fig. 3. ${ }^{(19)}$ A vacuum condition is kept in the multilayer membrane of the insulation plate. The thermal conductivity of the VIP is about $5 \mathrm{~mW} /(\mathrm{m} \cdot \mathrm{K})$, which is only one-sixth to one-tenth of that of conventional insulation materials. ${ }^{(18,19)}$ Aluminum foil with infrared reflection insulation is pasted onto both the outer surface of the PMMA and the inner surface of the VIP. This layout will achieve excellent thermal insulation performance.

\subsection{Design and simulation of the control system}

The measurement and control system is composed of nine refrigeration modules (each includes one $15 \mathrm{~W}$ thermoelectric cooler, two radiators, and one mini fan), a programmable power supply (PSM6003), a high-precision temperature sensor (Hart1504), and an industrial personal computer (IPC). The schematic diagram of the temperature control system is shown in Fig. 4. The thermoelectric cooler is used as a cooling actuator in this research. It can remove the heat load from one side to the other side based on the Peltier effect. ${ }^{(20)}$ The radiators are used to expand the contact area of the thermoelectric cooler with the air efficiently. The heat generated on the hot side of the thermoelectric cooler can be dissipated to the outside of the chamber by a mini fan. Hart1504 (resolution: $0.0001{ }^{\circ} \mathrm{C}$, accuracy: $0.003{ }^{\circ} \mathrm{C}$ ) is used to measure the temperature near the tip ball of the $\mathrm{CMM}$ probe. The temperature values output from Hart1504 are sent to the IPC via an

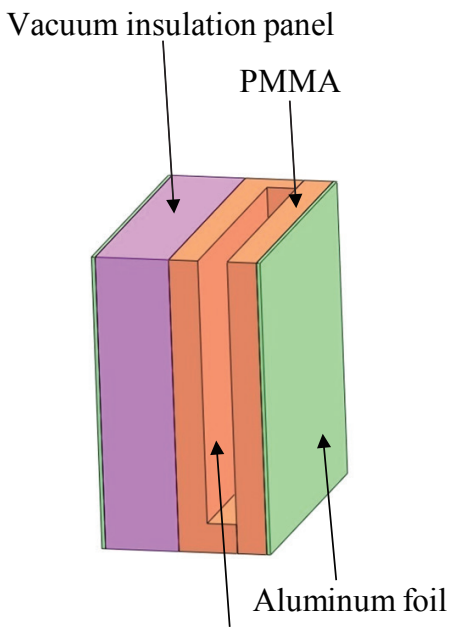

Hollow layer

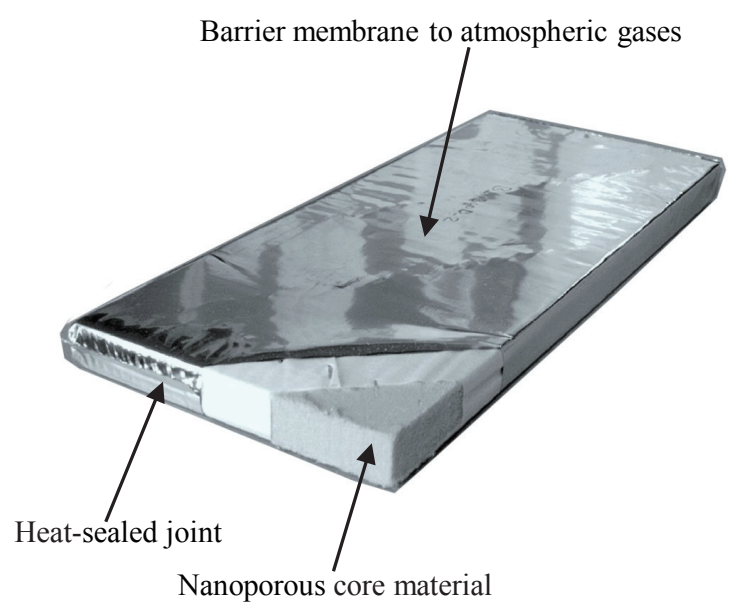

Nanoporous core material

Fig. 2 (left). (Color online) Thermal insulation wall.

Fig. 3 (right). Structure of the VIP. 


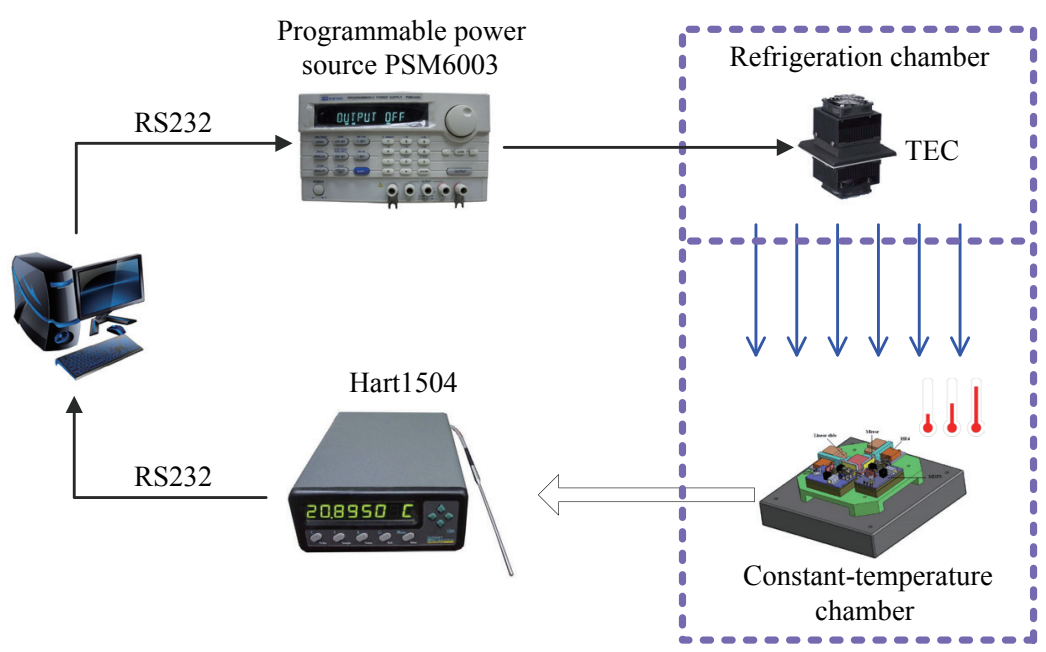

Fig. 4. (Color online) Schematic diagram of the temperature control system.

RS232 serial port. The proportional integral derivative (PID) controller is implemented by the IPC. PSM6003 can provide different current signals to the thermoelectric cooler according to the result of PID calculation.

\subsubsection{Temperature sensor calibration}

To measure the temperature field of the chamber, six Pt100 temperature sensors made by Fluke, a data acquisition unit (Agilent 34970A), and a 16-channel multiplexer module (Agilent 34902A) were adopted. The resolution and accuracy of Pt100 are 0.001 and 0.01 ${ }^{\circ} \mathrm{C}$, respectively. The functions of Agilent 34970A are to measure the resistance of Pt100 in real time and send the resistance value to the IPC via the RS232 port. The Pt100 temperature sensors were connected to Agilent 34970A via Agilent 34902A.

The Callendar-Van Dusen equation, shown as eq. (1), ${ }^{(21)}$ gives the relationship between the resistance of the Pt100 and the measured temperature.

$$
R(t)=R_{0}\left[1+a t+b t^{2}+c(t-100) t^{3}\right]
$$

Here, $t$ is the temperature, $R(t)$ is the resistance, and $R_{0}$ is the reference resistance when the temperature is $0{ }^{\circ} \mathrm{C}$. Although we have found the coefficients in eq. (1) from International Electrotechnical Commission (IEC) 751, namely, $R_{0}=100 \Omega, a=3.90830$ $\times 10^{-3}, b=-5.77500 \times 10^{-7}$, and $c=-4.18301 \times 10^{-12}$, we have to calibrate them by experiment again so as to reach a higher measurement accuracy for Pt100.

A standard platinum resistance of about $27 \Omega$ and a specialized constant-temperature trough, CTS-04IV (made in China), were used to calibrate the six Pt100 sensors. CTS- 
04IV, shown in Fig. 5, can generate different constant temperatures between 0 and $+95{ }^{\circ} \mathrm{C}$, the gradient of the temperature field in the trough is less than $0.01{ }^{\circ} \mathrm{C}$, and the transient process is less than $10 \mathrm{~min}$. The four-wire connection method was used when connecting the six Pt100 sensors to Agilent 34902A for reducing the effect of wire resistance. ${ }^{(22)}$ Considering that the required temperature in the chamber was 20 ${ }^{\circ} \mathrm{C}$, the resistances of the Pt100 sensors at approximately $20{ }^{\circ} \mathrm{C}$ had been calibrated primarily. The mean resistances of five determinations for each Pt100 sensor were obtained when the temperatures were set to $21.50,21.00,20.50,20.05,20.00,19.95$, and $19.90{ }^{\circ} \mathrm{C}$ separately, as shown in Table 1 . The relationship between the resistance and the temperature of each Pt-100 sensor could be obtained by the piecewise linear fitting method, one of which is shown in Fig. 6. Compared with the calibration method using eq. (1), the accuracy of the Pt100 sensor using this experiment could be improved by more than 0.2 ${ }^{\circ} \mathrm{C}$ and to better than $0.02{ }^{\circ} \mathrm{C}$ by this method; the errors are shown in Fig. 7 .

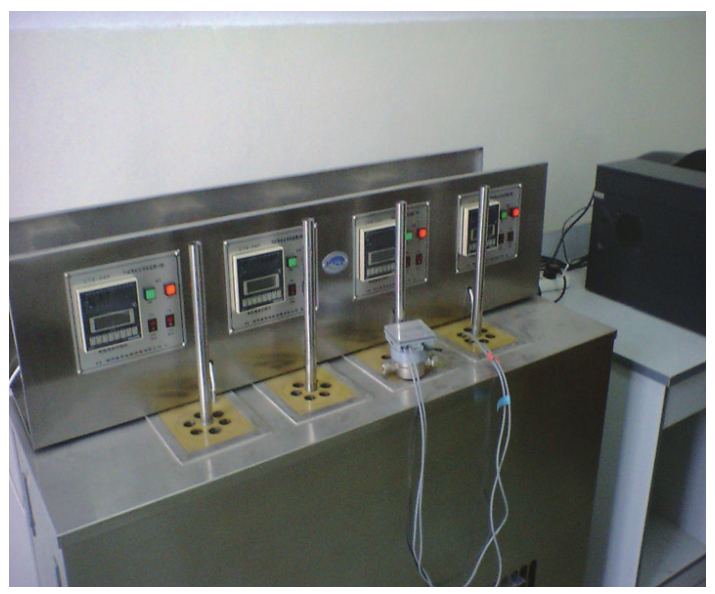

Fig. 5. (Color online) Photograph of CTS-04IV.

Table 1

Calibration results of the resistances.

\begin{tabular}{lrrrrrrr}
\hline & $19.90{ }^{\circ} \mathrm{C}$ & $19.95{ }^{\circ} \mathrm{C}$ & $20.00{ }^{\circ} \mathrm{C}$ & $20.05{ }^{\circ} \mathrm{C}$ & $20.50{ }^{\circ} \mathrm{C}$ & $21.00{ }^{\circ} \mathrm{C}$ & $21.50{ }^{\circ} \mathrm{C}$ \\
\hline Standard Pt100 $(\Omega)$ & 26.9968 & 27.0017 & 27.0064 & 27.0117 & 27.0566 & 27.1057 & 27.1553 \\
R1 $(\Omega)$ & 107.7017 & 107.7207 & 107.7404 & 107.7602 & 107.9350 & 108.1287 & 108.3238 \\
R2 $(\Omega)$ & 107.7212 & 107.7401 & 107.7597 & 107.7995 & 107.9548 & 108.1484 & 108.3423 \\
R3 $(\Omega)$ & 107.7045 & 107.7229 & 107.7427 & 107.7626 & 107.9381 & 108.1314 & 108.3259 \\
R4 $(\Omega)$ & 107.7403 & 107.7579 & 107.7784 & 107.7978 & 107.9726 & 108.1672 & 108.3612 \\
R5 $(\Omega)$ & 107.7174 & 107.7365 & 107.7549 & 107.7754 & 107.9509 & 108.1438 & 108.3384 \\
R6 $(\Omega)$ & 107.7283 & 107.7370 & 107.7561 & 107.7764 & 107.9520 & 108.1447 & 108.3395 \\
\hline
\end{tabular}




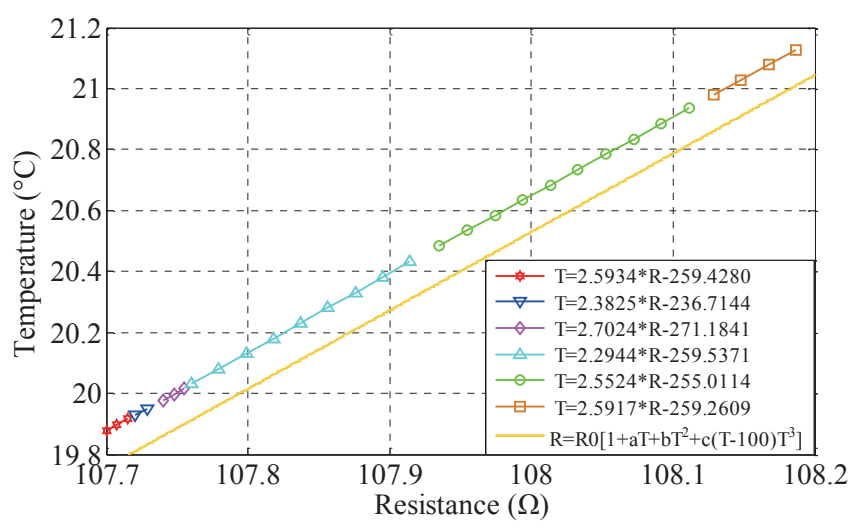

Fig. 6. (Color online) Calibration results of one Pt100 sensor.

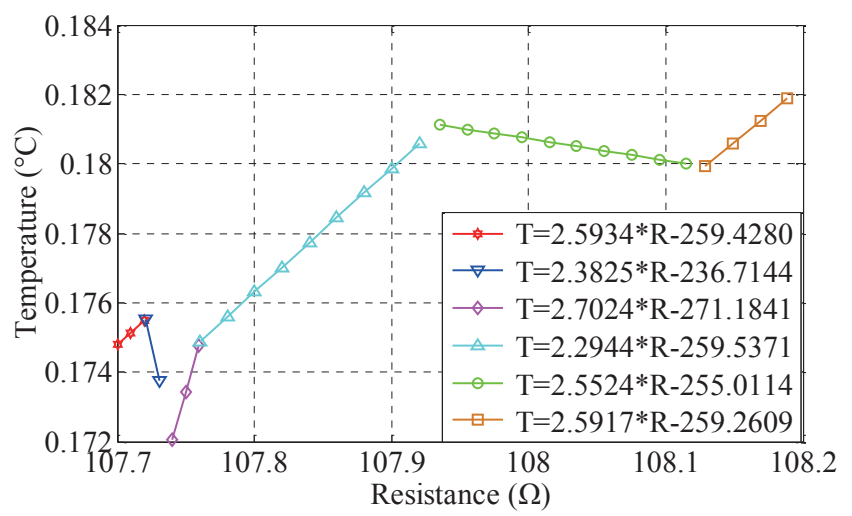

Fig. 7. (Color online) Calibration errors of Pt100 between the two calibration methods.

\subsubsection{System identification and control parameter settings}

It is vital to set the control parameters $(K p, K i$, and $K d)$ properly for the accuracy and stability of a control system. The control parameters rely on the characteristics of the controlled object and the entire system. A micro-CMM developed by our group was placed in the chamber (shown in Fig. 8). ${ }^{(16,17)}$ The traditional control parameter setting method usually requires at least three experiments since the three control parameters $(K p, K i$, and $K d$ ) have to be set and verified one by one. In this research, the system identification and simulation method were used to set the control parameters, and only one experiment was required.

The step response input method was adopted to identify the characteristics of the closed loop system. Firstly, a constant current of 1 A was supplied to each thermoelectric 


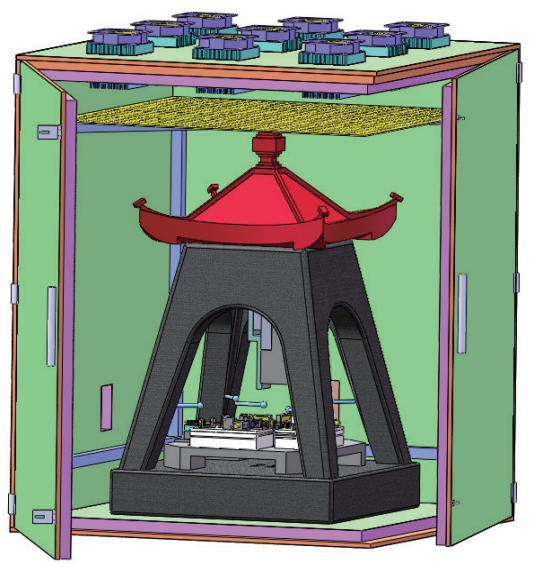

Fig. 8. (Color online) Illustration of the CMM and the chamber.

cooler in manual mode and we waited until the temperature in the chamber became stable. Secondly, a step current from 1 to 3 A was inputted to the control system and the temperature in the chamber was recorded synchronously until the system reached a new steady-state condition. Thirdly, system identification was carried out using MATLAB. A second-order transfer function of the system was obtained using eq. (2). Figure 9 shows the step input response curve obtained by experiment and by simulation based on the identified model: the two curves showed good agreement.

$$
G(s)=\frac{K}{T p 1 \times s^{2}+T p 2 \times s+1} e^{-\tau s}=\frac{5.6688}{2.5494 \times 10^{8} s^{2}+6.6655 \times 10^{4} s+1} e^{-189 s}
$$

The proper PID control parameters were gained by simulation using MATLAB software, namely, $K p=0.45, K i=0.016$, and $K d=0.03$. Figure 10 shows the simulation result of the system with low maximum deviation, small steady-state error, and fast transient time.

\section{Experimental Results}

To examine the performance of the constant-temperature chamber, some experiments were conducted when the Micro-CMM was in operation.

\subsection{Main temperature response measurement}

Hart1504, which measures the temperature of the probing point of the micro-CMM, was used as the feedback sensor. Another Pt100 was used to measure the temperature outside the chamber simultaneously. Figure 11 shows the transient response of the 

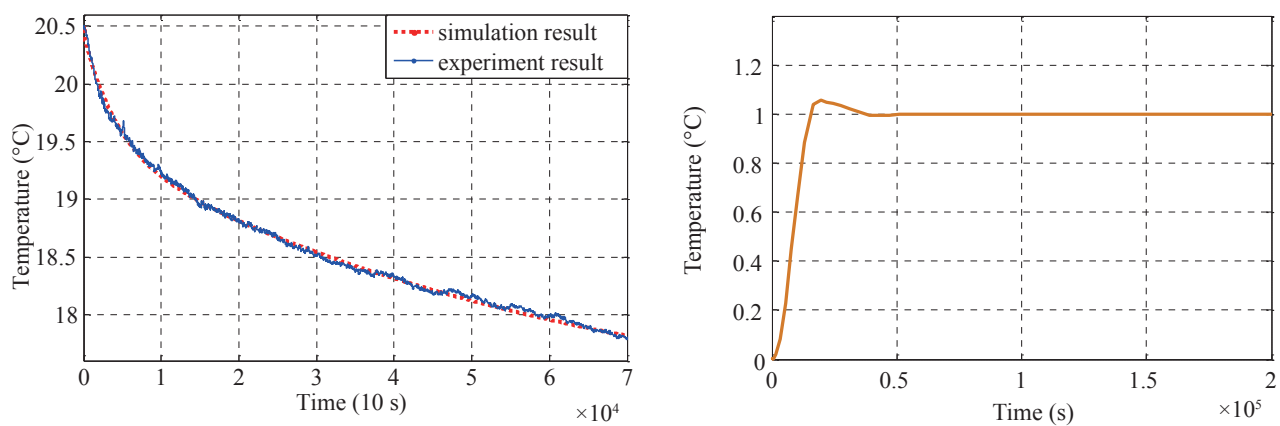

Fig. 9 (left). (Color online) Step input response of experiment and simulation.

Fig. 10 (right). (Color online) PID control simulation.

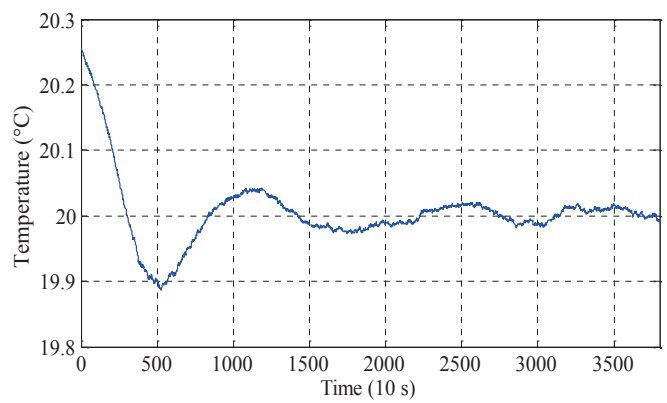

(a)

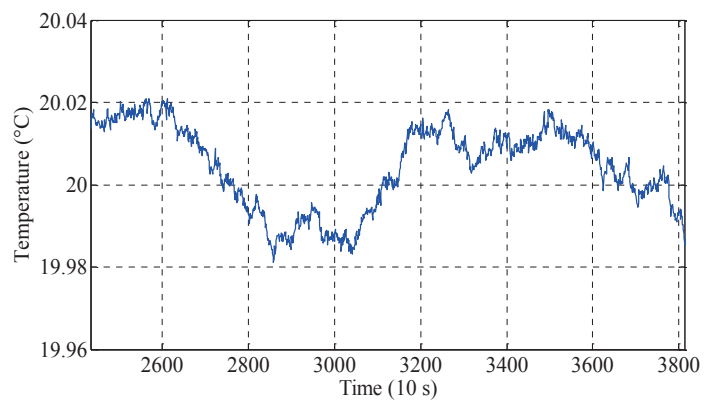

(b)

Fig. 11. (Color online) Temperature in the chamber: (a) time response and (b) at steady state.

control system and the temperature fluctuation under steady-state condition. It is seen that the transient process was about $4 \mathrm{~h}$; the steady-state error of the system was 0.0043 ${ }^{\circ} \mathrm{C}$ on average and the variation range was less than $\pm 0.02{ }^{\circ} \mathrm{C}$ when the set temperature was $20{ }^{\circ} \mathrm{C}$. The environment temperature of the chamber was varied between 21.5 and $22.5{ }^{\circ} \mathrm{C}$, as shown in Fig. 12. The stability of the temperature in the chamber was enhanced 25 times using the constant-temperature chamber.

\subsection{Temperature field measurement}

The temperature field in the chamber was also measured by locating six Pt100 temperature sensors, as shown in Fig. 13. Sensor (R5) at the probing point was used as the feedback sensor. R6 indicates the temperature outside the chamber. The other four temperature sensors (R1 to R4) were placed around R5 in horizontal and vertical positions separately. 


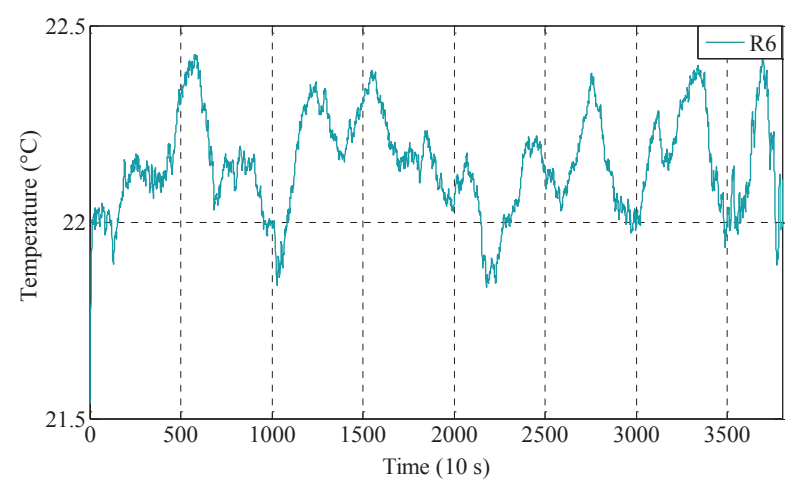

Fig. 12. (Color online) Temperature outside the chamber.

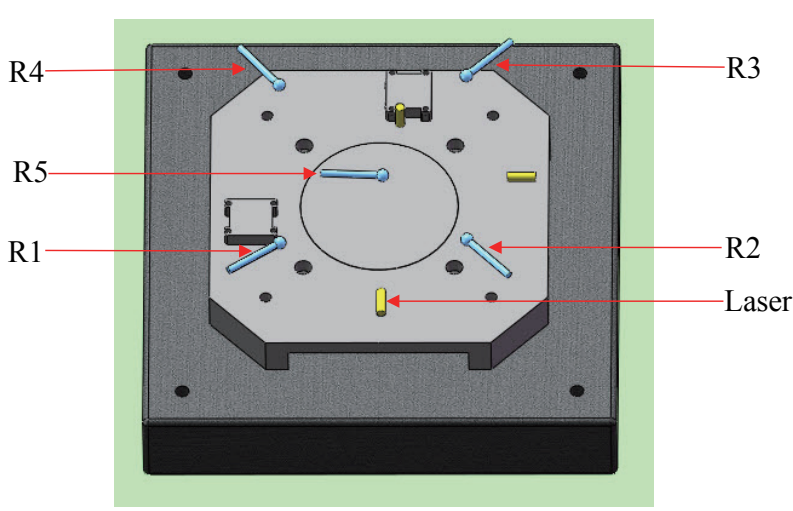

(a)

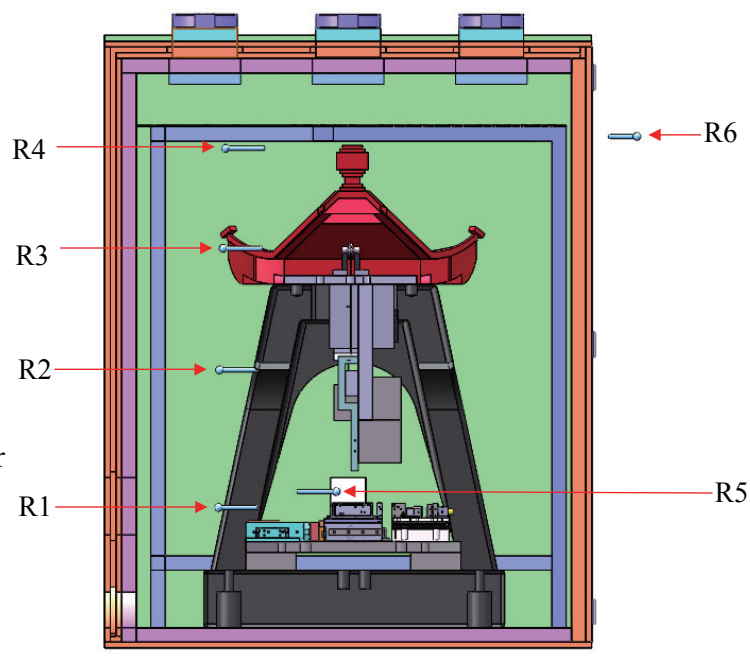

(b)

Fig. 13. (Color online) Distribution of the sensors when measuring the (a) horizontal and (b) vertical temperature fields.

Figure 14 shows the horizontal and vertical temperature fields fitted by the cubicspline interpolation method of MATLAB. The horizontal temperature variation is within $0.08{ }^{\circ} \mathrm{C}$. Near the side-opening door, there is an $8 \mathrm{~mm}$ gap between the hole plate and the inner wall, causing more cool air flows to this side. This is the reason why the temperature of R2 is lower and that of R4 is higher than that of the feedback point of R5. In the vertical field, since the refrigeration chamber has no fan to accelerate the speed of air flow, the temperature near the perforated plate is lower than the temperature of the feedback point by $0.2{ }^{\circ} \mathrm{C}$. 


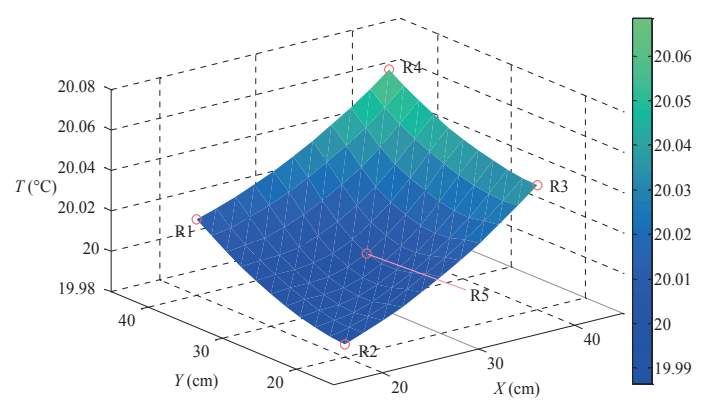

(a)

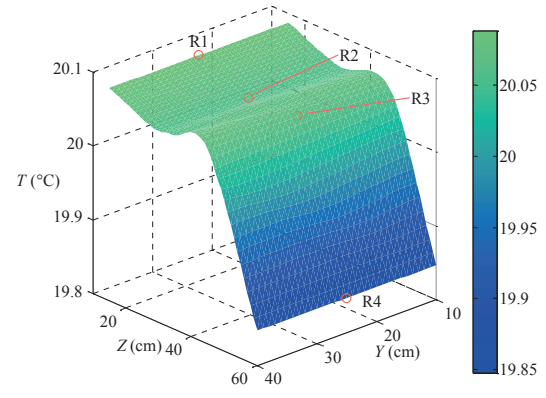

(b)

Fig. 14. (Color online) Temperature field in (a) horizontal and (b) vertical directions.

\section{Discussion}

The experimental results show that the designed system is reasonable and can achieve high-precision temperature control when placing the micro-CMM into the constanttemperature chamber. Note here that the Class I metrology room permits the temperature variation of $20 \pm 0.3{ }^{\circ} \mathrm{C}$ in the room and $20 \pm 0.1{ }^{\circ} \mathrm{C}$ in the vicinity of the measurement location, as specified by ISO Guide 25-1982. This study proves the achievement of a better temperature-controlled chamber than Class I.

\section{Conclusions}

In this research, we proposed a low-cost integrated constant-temperature chamber with high precision based on the natural convection principle. In the proposed design, the chamber is assembled using a hollow PMMA and a VIP with an ultralow thermal conductivity coefficient. It can achieve excellent thermal insulation and reduce energy consumption. Since there is no air supply system, the designed environment chamber is considered vibration-free. This system adopts the step input response method and system identification toolbox to obtain the system's mathematical model, so that the optimum PID parameters can be acquired by simulation using Simulink of MATLAB. The control system maintains temperature stability in the chamber by tuning the electric input current of the nine thermoelectric coolers according to the output of the PID controller. The experimental results show that the system's steady-state error is $0.0043{ }^{\circ} \mathrm{C}$ on average, and the variation range is less than $\pm 0.02{ }^{\circ} \mathrm{C}$ when the set value is $20{ }^{\circ} \mathrm{C}$. It has low energy consumption and is inexpensive, easily assembled, and superior to the normal Class I metrology environment. The mini environment chamber is not only suitable for micro-CMM measurement, but also applicable to all other micro/nanomeasurements. 


\section{Acknowledgements}

This work was part of a research program funded by the State Key Laboratory of Precision Measuring Technology and Instruments of China (PIL1401), the National Natural Science Foundation of China (51175141, 51275148), and the Natural Science Foundation of Anhui Province for Higher Education Institutions (Grant No. KJ2014A021).

\section{References}

1 J. A. Kramar: Meas. Sci. Technol. 16 (2005) 2121.

2 K. C. Fan, Y. T. Fei, X. F. Yu, Y. J. Chen, W. L. Wang, F. Chen and Y. S. Liu: Meas. Sci. Technol. 17 (2006) 524.

3 G. Jäeger, E. Manske and T. Hausotte: Proc. of 2001 Euspen's 2nd Int. Conf. eds. A. Balsamo, C. Evans, A. Frank, W. Knapp, G. Mana, M. Mortarino, S. Sartori and E. G. Thwaite (Euspen, Turin, 2001) p. 290.

4 K. Takamasu, K. R. Furutani and S. Ozono: Proc. of the XIV IMEKO World Congress. ed. J. Halttunen (IMEKO, Tampere, 1997) p. 34.

5 G. N. Peggs, A. J. Lewis and S. Oldfield: CIRP Ann. Manuf. Technol. 48 (1999) 417.

6 A. Küng, F. Meli and R. Thalmann: Meas. Sci. Technol. 18 (2007) 319.

7 S. W. Kim: Ann. Manuf. Technol. 50 (2001) 357.

8 International Organization for Standardization (ISO). ISO 14644-1, Clean rooms and associated controlled environments-Part 1: Classification of air cleanliness. http://www.iso. org.

9 International Organization for Standardization (ISO). ISO 14644-3, Clean rooms and associated controlled environments - Part 3: Metrology and test methods. http://www.iso.org.

10 International Organization for Standardization (ISO). ISO 14644-7, Clean rooms and associated controlled environments-Part 7: Separative devices (clean air hoods, glove boxes, isolators and mini environments). http://www.iso.org.

11 D. S. Lee, Z. D. Tsai and J. R. Chen: Proc. of the 2001 Particle Accelerator Conference. eds. P. Lucas and S. Webber (IEEE, Chicago, 2001) p. 2465.

12 C. Lynn: J. IES 37 (1994) 41.

13 P. Rerkkumsupand P. Prachprayoon. Proc. of the 3rd IEEE Int. Conf. on Nano/Micro Engineered and Molecular Systems (IEEE, Sanya, 2008) p. 432.

14 K. C. Fan, H. M. Wang and Y. C. Liu: Mater. Sci. Forum 594 (2008) 78.

15 H. Zhang, Z. Cai and K. C. Fan: Key Eng. Mater. 381 (2008) 65.

16 E. Manske, G. Jager, T. Hausotte and R. Fussl: Meas. Sci. Technol. 23 (2012) 074001.

17 K. C. Fan, F. Cheng, H. Y. Wang and J. K. Ye: Int. J. Nanomanuf. 8 (2012) 67.

18 H. Simmler, S. Brunner, U. Heinemann, H. Schwab, K. Kumaran, P. Mukhopadhyaya, D. Quenard, H. Sallee, K. Noller, E. K. Niarchos, C. Stramm, M. Tenpierik and H. Cauberg: Vacuum Insulation Panels - Study on VIP-components and panels for service life prediction of VIP in building applications Subtask A (2005).

19 M. Bouquerel, T. Duforestel, D. Baillis and G. Rusaouen: Energ. Buildings 54 (2012) 320.

20 S. Godfry: Electron. Cooling 2 (1996) 30.

21 V. C. Fernicola and L. Iacomini: Int. J. Thermophys. 29 (2008) 1817.

22 Keysight Technology Co.: Agilent 34970A/34972A User's Guide, http://literature.cdn. keysight.com/litweb/pdf/34972-90001.pdf, 2014. 